\title{
Walking the Talk: Enhancing Future Teachers' Capacity to Embed Social-Emotional Learning in Middle Years Classrooms
}

\section{Katherine Main}

School of Education and Professional Studies, Griffith University, University Drive, Meadowbrook QLD 4131, Australia; K.Main@griffith.edu.au; Tel.: +61-7-3382-1097

Received: 1 August 2018; Accepted: 6 September 2018; Published: 10 September 2018

\begin{abstract}
Early adolescence marks a developmental period during which there is a window of opportunity to explicitly teach and make a significant difference in a young person's development of social and emotional competencies (SECs). All students can benefit from the inclusion of SECs and failing to develop such SECs can result in poor outcomes in several domains including personal, social, and academic outcomes. Research on social and emotional programs for young adolescent learners has shown that a 'skills and drills' approach is far less effective than focusing on mind-sets and classroom climate. Although the role teachers play in explicitly teaching and supporting young adolescents' SECs has been recognised, teachers have reported a lack of confidence in knowing what, and how to teach these skills. This paper reports on a teacher education course that embedded social and emotional skills into both coursework design and assessment expectations. Results drawn from an analysis of students' responses to their main assessment task showed that pre-service teachers had a growing awareness of SECs and, in particular, were able to recognise the importance of focusing on the building of students' SEC s to support academic success across a broad range of curriculum areas.
\end{abstract}

Keywords: middle school; young adolescents; social and emotional competencies; teacher training

\section{Introduction}

As young people enter early adolescence, their main goals are to become independent and socially skilled [1]. During this time, they experience significant physical, cognitive and social and emotional changes while learning how to manage changing relationships with their parents and more complex relationships with their peers [2]. It is also a time when young people are transitioning to a secondary school setting with increased academic demands and an expectation that they are take on more personal responsibility. As part of the biological changes, young adolescents must navigate new and intense emotions. All of these changes and expectations require more mature social and emotional skills. Moreover, changes in brain structure and this increased hormone activity can make even minor social difficulties like being rejected by peers can be very hurtful and difficult to deal with. These biological changes also create a more intense thrill from risky behaviour, especially when it may win peers' admiration [1].

Social and emotional skills, have been categorised into five interrelated sets of competencies across a person's cognitive, affective and behavioural domains. These interrelated competencies include self-awareness, self-management, social awareness, relationship skills, and responsible decision-making [3]. Together, this suite of competencies forms the personal skills that are necessary for individuals to be able to connect with others and meet the challenges of life. Two meta-analyses around these competencies have shown that where children and adolescents improve their social and emotional skills they enjoy a greater sense of psychological wellbeing and academic performance $[4,5]$. 
More specifically, having well-developed social and emotional skills can help young people adapt to change and to be resilient, be more resourceful and find innovative and creative solutions to problems as well as being able to read and apply the necessary social cues to show respect and work well with others [4]. Having well-developed self-regulatory skills also means being able to make reasoned decisions and to take personal responsibility for actions and choices [6]. Importantly, Durlak et al. [4] and Sklad et al. [5] found a significant number of studies showed that these are not character traits, but rather, competencies that are malleable and can be taught.

Historically, the early years have been recognised as a critical time for the explicit teaching of social and emotional skills due to the malleability of the brain at this time [3]. More recently, advances in our understanding of neuroscience has also recognised that the major changes that are occurring in the brain during early adolescence provide another small but significant window of opportunity to explicitly teach and make a marked difference in the development of a young person's social and emotional skills [7]. As such, our increased understanding of the importance of social and emotional skills to complement and enable academic skills has seen an increase in interest in systematically promoting the development of these skills in schools and communities [8].

\subsection{Research on Social and Emotional Programmes for Young Adolescents}

Research on social and emotional programs for young adolescent learners have shown that a 'skills and drills' approach is far less effective than focusing on mindsets and classroom climate [9]. To date, most approaches to teaching social and emotional skills to young adolescents have been through 'aged-up' versions of programs developed for early childhood settings, however, for the most part, these programs fail to engage or motivate these young people [9]. In 2015, CASEL released the guide Effective Social and Emotional Learning Programs-Middle and High School Edition noted that "several innovative perspectives on educational practice are aligned with social and emotional learning [SEL] or create opportunities for SEL" (p. 32) [10]. These innovative perspectives were reported as programming changes that supported students in the classroom rather than specific, prescriptive programs. Further, the CASEL [10] guide recommended that a developmentally appropriate way to promote and enhance young adolescents' social and emotional skills was to use "specific teaching practices to create classroom environments that foster social and emotional learning" (p. 31) [10].

\subsection{Teachers}

Most teachers acknowledge that social and emotional skills are important and recognise the role that schools have to develop these competencies in students [11]. Although the role teachers play in explicitly teaching and supporting young adolescents' social and emotional skills has been recognised, teachers have reported a lack of confidence in knowing what and how to teach these skills [12]. Adding to the reluctance of teachers incorporating the teaching of social and emotional skills in the classroom, is the challenge of creating time and space in an already crowded curriculum. However, the importance of the role of teachers cannot be understated. Jennings and Greenberg [13] argued that teachers set the tone of the classroom through the development of relationships with and between students, providing clear behaviour expectations and learning goals, encouraging prosocial behaviour and by being a good role model of respectful and positive communications. As such, a teacher's ability to manage their own social and emotional competencies and sense of wellbeing was seen as critical to establishing a safe and supportive classroom environment.

In the report, To Reach the Students, Teach the Teachers: A National Scan of Teacher Preparation and Social \& Emotional Learning [8] it was observed that there was little or no congruence between the states' requirements for teacher education and what colleges of education were providing with almost no evidence of pre-service teacher education students (PSTEs) receiving training on how to actually promote SEL in the classroom. In addition, Schonert-Reichl et al. [8] found that PSTEs were being taught how to stop misbehavior rather than how to promote prosocial behavior. Yet, once these newly trained teachers have entered the profession, it is assumed that they have the requisite 
personal confidence, competence, and capabilities to create and maintain a safe and supportive learning environment, develop and sustain meaningful and effective relationships with students, colleagues, parents, and other school staff, be exemplary role models of self-regulatory behaviors. It is understandable when teachers appear to be resistant when confronted with an additional responsibility (i.e., teaching social and emotional skills) which is perceived as being additional to their already heavy and challenging workload [13].

A central tenet of This We Believe: Keys to Educating Young Adolescents [14] called for teachers to teach in the middle years to be those "who value young adolescents and are prepared to teach them" (pp. 15-16). Being "prepared to teach them" goes beyond just a willingness to teach, but more importantly, possessing the attitudes, skills and attributes to meet their educational needs. With a growing understanding of more effective forms of curriculum, pedagogy and assessment strategies that can engage and motivate young adolescents, the challenge for teacher-training organisations is to prepare teachers in a way that addresses the philosophical recognition of issues around alienation and underachievement in this age group [15]). That is, to support the awareness and development of teachers' capacity to support the development of students' social and emotional competencies.

\subsection{The Current Study}

This paper reports on a research project conducted within a one-year postgraduate secondary teacher education program in a large University in Brisbane, Australia. The aim of the study was to explore if embedding social and emotional skills in a teacher education course enhanced PSTEs' awareness of and willingness to embed the teaching of social and emotional skilling as part of their approach to classroom teaching. The underpinning theoretical focus used in this study was situated learning developed by Lave and Wenger in the early 1990s. Their approach posits that students learn best when they are actively involved in the learning experience. Thus, it can be argued that situated learning facilitates the development of the knowledge and understandings necessary to respond in particular situations and draws on Dewey's pragmatic views linking actions to consequences [16]. By situating the student in the learning activity, new knowledge and understanding is gained through an authentic experience. Further, within this type of learning, the student transforms from novice to expert through their active participation within a context and through their interactions with others [17]. For PSTEs, exploring the developmental attributes of young adolescent learners through a range of activities intended to teach and develop social and emotional skills within an authentic situated learning context also supports their growth as adaptive experts in that they are able to transfer knowledge and practices gained in one situation and transfer this knowledge into their teaching practices.

\section{Method}

The research question addressed in the study were:

- Does participation in an applied and embedded social and emotional learning experience result in higher levels of awareness of SES?

- Does participation in an applied and embedded social and emotional learning experience result in PSTEs awareness of SEL in different curriculum areas? 


\subsection{Participants}

Invited participants included all students $(\mathrm{N}=342)$ who were enrolled in a core course within a postgraduate teacher education program. This core course focused on the developmental characteristics of young adolescents and the implications for practice and aimed to develop pre-service teachers' understanding of the theory to practice nexus and to ensure their future teaching practices/approaches supported the developmental stage of early adolescence. Approaches to developmentally appropriate pedagogy were overtly modelled by the lecturer and tutor and opportunities for incidental teaching were regularly explored. Students studying this program were preparing to teach in Australian secondary schools (Years 7-12) and, as such, are required to specialise in two key learning areas (KLAs). KLAs studied can be a combination of any of the following: English, mathematics, science, Languages other than English (LOTE), Geography, History, Information and Communication Technologies (ICTs), Health and Physical Education (HPE), The Arts (Visual Art and/or Drama), and Business.

After final grades for the semester had be released, all students were sent an online questionnaire asking for permission to access their final assessment task for research purposes. Students had to simply indicate a Yes or No response. Of the 342 PSTEs enrolled in the course, 218 gave permission for their final assessment tasks to be used by the researcher. A research assistant was employed to match the affirmative responses with the electronic assessment submissions and to download and de-identify each task. Table 1 outlines the response rate and demographics of the participants. This paper will report on the themes within the rationales (focus) of students' research papers and does not go into a fine-grained analysis of specific strategies in the final action plans. This decision was made as the PSTEs were able to select any issue relevant to their teaching areas and that the structure of rationales demonstrated the focus and the intent of the PSTEs to embed SES when teaching young adolescent learners. PSTEs' rationales were written as a personal narrative where the PSTE was able to explain and justify their choice of focus. As the PSTEs did not have an opportunity to apply and be given feedback on the embedding of SES in a classroom context, it was decided that the hypothetical nature of the action plans would not be used in this paper.

Table 1. Number and make-up of participants.

\begin{tabular}{ccc}
\hline Total Participant Pool & Male & Female \\
\hline 342 & $142(41 \%)$ & $200(59 \%)$ \\
Agreed to Participate & & \\
$218(64 \%)$ & $82(38 \%)$ & $136(62 \%)$ \\
\hline
\end{tabular}

The research reported in this paper was linked to a first semester course that involved eight weeks of on-campus coursework delivered face-to-face that included a two-hour lecture and a two-hour tutorial each week. The course content was based around understanding both the developmental characteristics of the young adolescent learner as well as developmentally appropriate teaching practices.

\subsection{Course Design}

An embedded design principle was used in the course design [18]) with the aim of the weekly tutorials was to model how specific social and emotional skills could be embedded within the context of classroom work. During each week, tutors were instructed to discuss not just the content that was being presented but also to explain the incidental teaching of the social and emotional skill/s for that week. In line with Bain's [18] model, the embedded design principle was implemented at four levels: They were:

Level I: knowledge and awareness-Lectures and required readings introduced students to the developmental characteristics of young adolescents and, in particular, the interrelatedness of the physical, cognitive and social and emotional domains. Additional resources linked to a specific social 
and emotional competency were provided on the course web-site each week and students were made aware of these additional resources which provided a range of examples of SES strategies that PSTEs could apply to enhance their own SES and support their own university studies. An exam in Week six focused on the content for the first five weeks of the course based on one of the key objectives of the course that PSTEs demonstrate an understanding of the interrelatedness of the developmental characteristics of young adolescent learners.

Level II: active experience-At this level, tutorials were used to translate knowledge and awareness into classroom practice through a range of learning activities conducted each week in the tutorials. Throughout the eight-week teaching semester, students attended two-hour weekly tutorial where tutors modelled the embedding and teaching of a key SES. PSTEs participated in activities to learn the weekly content that highlighted and provided opportunities to teach a particular SES. A discussion explaining the SES, its importance for young adolescent learners and how it could be embedded in daily classroom activities across the different curriculum areas was also conducted each week. The importance of SES as academic enablers was continually reinforced.

Level III: continuous application and feedback-Bain's [18] embedded design principle requires that key strategy elements/skills are embedded in all aspects of the course. This embedding was achieved through the weekly focus on SES, the course content, additional activities and support resources on the course site. Feedback was achieved through PSTEs demonstrated understanding of the interrelatedness of the developmental characteristics of the young adolescent learner in their exam as well as being a key focus of their research task and action plan (final assessment).

Level IV: personal impact-At the personal impact level, Bain's [18] embedded design has a direct effect on the student's SES. The PSTEs use the SES in ways that have a positive effect on their own study habits, interpersonal relationships, awareness of and improvement in self-regulatory skills, cooperative skills, and communication skills. For example, in Week one, as part of the housekeeping for the course, tutors were asked to outline and explain the assessment for the course. The social and emotional skill being targeted for the week was responsible decision-making. Students were asked to make a study plan for the semester and include assessment due dates and when revision of notes or drafts of assignments should be completed. A discussion followed around the benefits of planning and reminders to prioritise their study and was linked to the social and emotional skill of responsible decision-making. As such, the embedding of SES was intended to support PSTEs own SES as well as their confidence and competence to embed a range of the skills into their everyday practice.

Each week, the tutorials were planned to deliver course content through a particular social and emotional skill. Table 2 outlines the eight-week plan provided to tutors. A different skill was used each week and these skills were drawn from the five key sets of competencies outlined by CASEL [3], namely, self-awareness, self-management, social awareness, relationship skills, and responsible decision-making. At least one specific social and emotional skill was selected from each of the five key sets. 
Table 2. Tutors guide to content and social and emotional skill focus with suggested activity.

\begin{tabular}{|c|c|c|c|}
\hline Week/s & Content & Social and Emotional Skill & Activity \\
\hline \multirow{3}{*}{1} & \multirow{3}{*}{$\begin{array}{l}\text { Understanding "middle years" and } \\
\text { "Junior Secondary" Concepts and } \\
\text { definitions including: Adolescence and } \\
\text { adolescent development (physical, } \\
\text { cognitive, emotional. }\end{array}$} & \multirow{3}{*}{$\begin{array}{l}\text { Responsible decision making: Being able to make flexible and } \\
\text { responsible decisions and problem solve through a process of } \\
\text { weighing options and considering the consequences. This competency } \\
\text { also includes being able to create and execute a plan, make an } \\
\text { evaluation of its effectiveness considering the facilitators and barriers } \\
\text { and then revise the plan to achieve the desired aims or objectives. } \\
\text { Key skills in this category: Imagining alternative ways of doing things, } \\
\text { applying learning in new contexts, enterprising, innovating, remaining } \\
\text { open to new ideas, Planning and Problem Solving-navigating } \\
\text { resources, organising, setting and achieving goals, decision-making, } \\
\text { researching, analysing, critical thinking, questioning and challenging, } \\
\text { evaluating risks, reliability. }\end{array}$} & $\begin{array}{l}\text { Decision making guide } \\
\text { Use an activity from the decision-making guide to create an } \\
\text { activity using the content from this week. }\end{array}$ \\
\hline & & & $\begin{array}{l}\text { Suggested activity: } \\
\text { Discuss the necessary steps in decision making: } \\
\text { 1. Identify your choices } \\
\text { 2. What's best for you now? } \\
\text { 3. Consider others-Not only me } \\
\text { 4. Consider your future-Not only now } \\
\text { 5. Make a choice and go for it }\end{array}$ \\
\hline & & & $\begin{array}{l}\text { Have each student make a study plan for the semester to } \\
\text { incorporate planning for assessment. }\end{array}$ \\
\hline & \multirow{2}{*}{$\begin{array}{l}\text { Overview of brain development and } \\
\text { implications for classroom teaching } \\
\text { including strategies and practices that } \\
\text { help students gain, process, and apply } \\
\text { content and skills. }\end{array}$} & \multirow{2}{*}{$\begin{array}{l}\text { Self-awareness: Being self-aware means having the ability to reflect } \\
\text { on and to accurately identify one's emotions and thoughts and to } \\
\text { recognise how these emotions and thoughts can influence behaviour. } \\
\text { It is also recognising personal growth (physical, cognitive, social, and } \\
\text { emotional) and change and making adjustments to ensure continued } \\
\text { connectedness with others. } \\
\text { Key skills in this category: Confidence and Agency-self reliance, self } \\
\text { esteem, self-efficacy, self belief, ability to shape your own life and the } \\
\text { world around you. }\end{array}$} & $\begin{array}{l}\text { Self-awareness activity. Use an activity from the chapter on } \\
\text { self-awareness to have students explore their own experiences } \\
\text { during adolescence-around their development, adjustments, } \\
\text { friendships etc. }\end{array}$ \\
\hline & & & $\begin{array}{l}\text { Discuss how this could be used in a classroom. In what ways could } \\
\text { you teach this concept incidentally in mathematics, English, } \\
\text { History, etc. to challenge their thinking and increase their } \\
\text { connectedness to learning? (Possible link to Dweck's Growth } \\
\text { mind-set work-if students have negative perception of } \\
\text { themselves-e.g., I am not good at maths). }\end{array}$ \\
\hline & \multirow[t]{2}{*}{$\begin{array}{l}\text { The focus of this week is on supporting } \\
\text { adolescents through transitions, } \\
\text { including topics-Student } \\
\text { well-being-Resilience-Social and } \\
\text { Emotional Development. }\end{array}$} & \multirow{2}{*}{$\begin{array}{l}\text { Self-management: Being able to recognise and regulate emotions, } \\
\text { thoughts, and behaviours appropriately in a range of different contexts. } \\
\text { It also includes being able to manage stress and being able to set and } \\
\text { achieve a range of personal and academic goals, and being persistent. } \\
\text { Key skills in this category: Self discipline, self-management, } \\
\text { self-motivated, concentrating, having a sense of purpose, persistent, } \\
\text { self-controlled. }\end{array}$} & $\begin{array}{l}\text { Self-management involves recognising and regulating emotions, } \\
\text { thoughts, and behaviours. It is about action before distraction or } \\
\text { reaction-so being prepared and giving yourself the best possible } \\
\text { chance of success. Read some of the activities in the } \\
\text { self-management slide share. Discuss in small groups the ways } \\
\text { that you learn best and what actions you can take to maximise } \\
\text { your learning. For example, taking notes to help listening, not } \\
\text { sitting next to someone who distracts you, turning off your phone. }\end{array}$ \\
\hline & & & $\begin{array}{l}\text { Resilience: There are also a number of activities to teach about } \\
\text { resilience. Select a game that can be played to talk about learning } \\
\text { from mistakes and how to improve. }\end{array}$ \\
\hline
\end{tabular}


Table 2. Cont

\begin{tabular}{|c|c|c|c|}
\hline Week/s & Content & Social and Emotional Skill & Activity \\
\hline & \multirow{2}{*}{$\begin{array}{l}\text { The focus of this week is to understand } \\
\text { student engagement and student } \\
\text { motivation. We will examine the } \\
\text { engagement continuum and look at what } \\
\text { student engagement is and how to } \\
\text { engage and motivate students in Junior } \\
\text { Secondary classrooms. Signature } \\
\text { practices for this age group will also be } \\
\text { explored. }\end{array}$} & \multirow{2}{*}{$\begin{array}{l}\text { Social awareness: Being able to have empathy and consider the } \\
\text { feelings and perspectives of others, being non-judgemental of others, } \\
\text { and being assertive when necessary. Students often confuse being } \\
\text { assertive with bullying behaviours. } \\
\text { Key skills in this category: Reviewing, self-awareness, reflecting, } \\
\text { self-regulating, self-accepting, Good communication - explaining, } \\
\text { expressing, presenting, listening, questioning, using different ways of } \\
\text { communicating. }\end{array}$} & $\begin{array}{l}\text { Among other things, good listening is key to students being able to } \\
\text { consider the perspectives and feelings of others. Part of good } \\
\text { listening is to use active listening. As the SEL activity this week, } \\
\text { use the topic of student engagement to start group conversations } \\
\text { and have students use active listening skills. }\end{array}$ \\
\hline & & & $\begin{array}{l}\text { You may also choose another topic/activity from this resource on } \\
\text { social-awareness. }\end{array}$ \\
\hline & $\begin{array}{l}\text { The focus for this week is on catering for } \\
\text { the diverse student populations in junior } \\
\text { secondary classrooms. Topics covered } \\
\text { will include differentiation and } \\
\text { personalised learning. }\end{array}$ & $\begin{array}{l}\text { Relationship skills: Being able to initiate, establish, and maintain } \\
\text { positive relationships with others, including those from diverse } \\
\text { backgrounds. Relationship skills also include communication skills, } \\
\text { negotiation skills, conflict management skills as well as being able to } \\
\text { seek and offer help when needed. } \\
\text { Key skills in this category: Relationships and Leadership-motivating } \\
\text { others, valuing and contributing to team working, negotiating, } \\
\text { establishing positive relationships, interpreting others, managing } \\
\text { conflicts, empathizing. }\end{array}$ & $\begin{array}{l}\text { Conflict management is a key social competency. Many people } \\
\text { avoid conflict and will let things fester. This resource has a huge } \\
\text { range of activities that are aimed at younger children but can be } \\
\text { easily adapted for young adolescents. Select an activity around } \\
\text { compromising or conflict management. Use the content from this } \\
\text { week's readings to create a scenario of two teachers working } \\
\text { together and the potential conflicts that may arise. For example: } \\
\text { 1. I like playing music in my room when students are } \\
\text { working-your teaching partner does not. How can you resolve } \\
\text { this? } \\
\text { 2. A colleague borrowed some of your resources and you need } \\
\text { them. You have already asked for them back twice and they have } \\
\text { still not been returned. What can you do? }\end{array}$ \\
\hline
\end{tabular}




\subsection{Data Collection}

Data for this project consisted of the 'Rationale and focus question' (Section 1) from their main assessment task for the course. Ethical clearance was obtained through the university and at the end of the teaching period, students were asked via email to indicate by responding to a "Yes" or "No" online poll, for the researcher to have access to their final research project which included their classroom action plan. The main assessment task for the course required students to undertake a 2500 word structured research project around a topic of interest related to young adolescent learners and one of their teaching areas. The aim of the task was to provide students the opportunity to consider their teaching areas and their new understandings around the developmental characteristics of middle years learners and implications for practice. This approach directly linked the task to students' future classroom practice to maximize the learning that has taken place (Lawrence \& Butler, 2010). The research task (see Table 3) is outlined below.

Table 3. Research task.

Throughout this course, you will explore a range of issues that relate to the physical, social, emotional and cognitive developmental aspects of adolescence as well as a number of significant social, economic and cultural issues relevant to the lives of young people in junior secondary school settings. Alone and in combination these issues directly affect you as a teacher. As a future teacher of young adolescent learners, this task requires you to identify an issue or a combination of issues that may directly impact on your classroom practice. You will be required to:

- Select an issue or appropriate combination of issues that may affect young adolescents in the classroom (approximately 11-15 Years).

- $\quad$ Research this topic within the specific context of adolescence and the particular relevance it might have for you as a teacher.

- $\quad$ Research the best ways of working with young people in respect of this issue.

- Reflect upon implications of this issue for student learning and your teaching practice.

- $\quad$ Genre: Research-based discursive essay

The essay may be written in the first person and students must frame their research paper in six sections:

1. Rationale for research focus together with a focus question/s.

2. Literature review (analysis and synthesis of literature around the issue/s).

3. Reflect on the research in terms of how it answers to your focus questions and any new questions.

4. How has this research influenced your thinking around your future practice?

5. Future action plan for practice (Explain how you will apply this new understanding into your future teaching practice, justify and give practical examples in context).

6. Reference list

\subsection{Data Analysis}

The analysis proceeded in two steps. First, students' research assignments $(\mathrm{n}=218)$ were de-identified and sorted according to their KLA focus. Nine categories were established, including eight KLAs and one general area, including Science $(n=36)$, Mathematics $(n=61)$, Health and Physical Education $(n=60)$, English $(n=22)$, Information and Communication Technologies $(n=17)$, Business $(n=6)$, The Arts $(n=6)$, Geography $(n=6)$, general classroom $(n=4)$. The second phase of the analysis was twofold: (a) to ascertain PSTEs levels of awareness of SES when teaching young adolescent learners; and (b) were PSTEs able to include the teaching of social and emotional skills across a broad range of curriculum areas.

To understand students' awareness of the importance of teaching social and emotional skills, the rationale from each assignment was $(n=218)$ was analysed by hand coding each piece of text line by line. The word count guide provided to PSTEs for the rationale and focus questions was approximately 300 words. The researcher used a predetermined set of keywords based on the five competency sets outlined by CASEL [3] to code either a positive (evident) or negative (not evident) inclusion of social and emotional skills. Table 4 outlines the keywords used to analyse the rationales. 
Each rationale was carefully read by two people and agreement was made in relation to the use and intent of keywords and phrases. Each keyword and phrase was then checked for phrasing to determine if the word directly related to the intended justification of the social and emotional skill within the KLA or if it was a more generalised statement. For example, the word motivation was used consistently, however, for the most part, the word motivation was used in a context to describe how the teacher would motivate students rather than promoting students' ability to be self-motivated. Used in this way, a negative or not evident coding was applied. In other instances, the word motivation was linked to goal setting demonstrating the intent to build students' competencies and a positive or evident coding was applied.

Table 4. Social and Emotional Competencies-Keywords.

\begin{tabular}{ll}
\hline \multicolumn{1}{c}{ CASEL's 5 SEL Competencies } & \multicolumn{1}{c}{ Keywords } \\
\hline $\begin{array}{l}\text { SELF AWARENESS (SA) } \\
\text { The ability to accurately recognize one's own } \\
\text { emotions, thoughts, and values and how they } \\
\text { influence behaviour. The ability to accurately }\end{array}$ & $\begin{array}{l}\text { Labelling one's feelings } \\
\text { Relating feelings and thoughts to behaviour } \\
\text { Accurate self-assessment of strengths/challenges } \\
\text { assess one's strengths and limitations, with a } \\
\text { well-grounded sense of confidence, optimism, } \\
\text { and a "growth mind-set". }\end{array}$ \\
$\begin{array}{l}\text { Self-efficacy } \\
\text { Optimism }\end{array}$
\end{tabular}

\section{Self-Management (SM)}

The ability to successfully regulate one's emotions, thoughts, and behaviours in different situations-effectively managing stress, controlling impulses, and motivating oneself. The ability to set and work toward personal and academic goals.

Social Awareness (SocA)
The ability to take the perspective of and
empathize with others, including those from
diverse backgrounds and cultures. The ability to
understand social and ethical norms for
behaviour and to recognize family, school,
and community resources and supports.

\section{Relationship skills (RS)}

The ability to establish and maintain healthy and rewarding relationships with diverse individuals and groups. The ability to communicate clearly, listen well, cooperate with others, resist inappropriate social pressure, negotiate conflict constructively, and seek and offer help when needed.

\section{Responsible Decision Making (RDM) \\ The ability to make constructive choices about personal behaviour and social interactions based on ethical standards, safety concerns, and social norms. The realistic evaluation of consequences of various actions, and a consideration of the well-being of oneself and others.}

Regulating one's emotions

Managing stress (anxiety)

Self-control

Self-motivation/perseverance/grit

Setting and achieving goals

Organisation skills (organising, researching, analysing, critical thinking, questioning, evaluating) Impulse control

Generalise what they have been taught-transfer of skills

\section{Perspective-taking}

Empathy

Appreciating diversity

Understanding social and ethical norms for behaviour

Recognizing family, school and community supports

Building relationships with diverse

individuals/groups

Communicating clearly (explaining, expressing, presenting. Listening, questioning, different ways of communicating)

Working cooperatively

Resolving conflicts

Seeking help

Considering the well-being of self and others Recognizing one's responsibility to behave ethically Basing decisions on safety, social and ethical considerations

Evaluating realistic consequences of various actions

Making constructive, safe choices about self,

relationships and school

Problem solving

Reflection

Self-direction 


\section{Results}

The results of the analysis of the data will be explained by each KLA and outline (a) the number of assessments where it was evident that social and emotional competencies were to being overtly part of their research focus, and (b) the key competencies that were described within those assignments.

\subsection{Science $(n=36)$}

Of those students who focused their assignments within the science teaching area, only seven (19\%) focused on social and emotional skills. Of these, the key competencies in order of frequency included the use of group-work to promote cooperative learning, setting and achieving goals, organisational skills, seeking help, and developing a growth mind-set. Although there was concern raised about anxiety associated with studying science, particularly for girls, in general this issue was addressed through teaching strategies associated with 'fun' and 'games' and 'careful scaffolding of tasks' to support learning rather than the use of SES to promote academic outcomes.

\subsection{Mathematics $(n=61)$}

Of those students who focused their assignments within the mathematics teaching area, 22 (33\%) focused on social and emotional skills. Of these, the key competencies in order of frequency included setting and achieving goals, group-work to promote cooperative learning, seeking help, and growth mind-set. One student also included strategies for self-reflection. Mathematics was also a KLA where anxiety and preconceptions about being bad at mathematics was raised. Responses to address students' anxiety again included teaching strategies associated with 'fun' and 'games' and also the teaching being a positive role model by showing enthusiasm for the subject area. It was proposed that by being enthusiastic that they could 'eventually influence' their students.

\subsection{Health and Physical Education $(n=60)$}

Health and Physical Education has a number of specific curriculum sub-strands that include the teaching of specific social and emotional skills (i.e., help-seeking, making healthy and safe choice, interacting with others, understanding emotions, teamwork and leadership, and valuing diversity) As such, it was expected that a large proportion of assignments in this KLA would address areas within the curriculum that focus on social and emotional competencies. However, although more than other KLAs 35 (58\%) focused on social and emotional skills. Of these, the key competencies in order of frequency included relationships and cooperative learning, setting and achieving goals, and growth mind-set. Providing students some choice was referred to in nearly every assignment and was also strongly linked to motivation. One assignment also included strategies for self-reflection.

\subsection{English $(n=22)$}

Within the English assignments, only two (1\%) focused on social and emotional learning. The key competencies included were relationships and cooperative learning. There was a strong focus on 'skilling and drilling' within English with some reference to the choice of texts to 'probably spark motivation'.

\subsection{Information and Communication Technologies $(n=17)$}

Interestingly, 12 (71\%) of the assignments within this KLA focused on some social and emotional competency with relationships and responsible decision making being referred to in all of these assignments. The context of these competencies was to build students' awareness of online safety (responsible decision making) and to build respectful relationships in the online space. The other five assignments all focused on skill development with ICTs. 


\subsection{Business $(n=6)$}

Fifty per cent (3) of the assignments had some focus on social and emotional competencies. Relationships and cooperative learning were the most common competencies with group tasks and students working in teams to develop business models.

\subsection{The Arts $(n=6)$}

Although there were only six assignments that covered The Arts KLAs, those that focused on social and emotional competencies (50\%) included relationships and cooperative learning but also looked at 'building confidence' to handle 'trauma' and developing resilience. Assignments within the Arts also covered more contemporary issues such as gender, sexuality and identity.

\subsection{Geography $(n=6)$}

Within this KLA, only one (17\%) focused on social and emotional learning. The key competencies included were relationships and cooperative learning through the use of group work.

\subsection{General Classroom $(n=4)$}

None of the assignments that focused on general classroom practices included any social and emotional competencies. For the most part, these assignments addressed ways to cater for the physical changes that are occurring during adolescence including the size of furniture and the importance of movement or on students with special needs.

\section{Discussion}

Through modelling and using incidental teaching practices, tutors embedded at least five social and emotional competencies within their weekly tutorials over the duration of the course. This approach provided an authentic learning experience for PSTEs as well as the modelling of suitable strategies that could be applied into their future practice. The PSTEs were able to select any issue of concern that related to their future classroom practice and, at first glance, from the rationales used within the analysis, there appeared to be a limited number of social and emotional competencies included within the assignments. However, on closer examination, at least one of the five key skills that were included and modelled in the weekly tutorials were in each assignment and many assignments highlighted two or more skills. What was noted, however, was that the most common SES were cooperative learning and relationship building (as companion skills). It could be argued that these skills are the easiest to implement within daily classroom practices for this age group, particularly in light of the increased importance of peer relationships during early adolescence. The most frequently included competencies in order were cooperative learning (Week 4), relationships Week 5), setting and achieving goals, self-management (Weeks 1 and 3), and developing a growth mind-set (Week 2).

With the two key aims of the course being for PSTEs to understand both the developmental characteristics of the young adolescent learner as well as developmentally appropriate teaching practices, it was encouraging to see so many PSTEs begin to recognise and consider teaching practices that addressed the social and emotional developmental needs of young adolescent learners. However, without overtly expecting students to include a focus on embedding SES, only 39\% of respondents included SES explicitly in their assignments. The results also showed that PSTEs who focused their research assignments on English, mathematics and science, were the least likely of the PSTEs to include the use of SES within their rationales, i.e., 1\%, 19\% and 33\% respectively. However, many of the rationales in mathematics and science included terms such as 'fun', 'games', 'scaffolding', 'enthusiasm', and 'motivation'. Many of these terms can be found within the words describing CASEL's five key social and emotional competencies. How these PSTEs understood and described SES may mean that they were attempting to incorporate SESs but their descriptions did not meet the criteria for inclusion in the analysis count. For the most part, the PSTEs who chose a topic linked to English, were more 
focused on improving their pedagogical approach to teaching English content as a means to addressing the needs of the young adolescent learner. It should also be noted that, as a research assignment, PSTEs needed to use literature to support their ideas. With limited literature around embedding SES within curriculum areas, PSTEs may have chosen to frame their assignment in such a way as to ensure they had a sufficient literature base to support their work.

Many of the PSTEs rationales were written as a personal narrative reflecting on their own high school experiences. For some it was an epiphany as to why they struggled or succeeded in certain subjects in high school; for others it was confirmation that a particular teacher or teaching approach was good practice. All students who included the use of one social and emotional skill within their rationale, linked the SES as a means to enhance students' academic outcomes which demonstrates that these PSTEs were considering the learning needs of adolescent learner.

It has been said that 'primary teachers love their students and that high school teachers love their subject', implying that high school teachers historically have not considered the need to cater for the developmental characteristics of all the students they teach. However, for these, 'soon to be' high school teachers there was a growing awareness that, in many instances, students' 'anxiety' towards particular subjects may be abetted through embedding SES in their daily classroom practice. For example, a number of students commented that incorporating language that supported a growth mind-set [19] had the potential to change both the way they perceived their students' ability and the way their students perceived their own ability in certain curriculum areas. It could be argued that the PSTEs who included SES in their rationales recognised the importance of SES and that they could be embedded within their daily practice in more subtle ways rather than a skills and drills approach [9]). That is, within their assignments, PSTEs were able to explain how to use SES as the medium for teaching the content of their particular subjects.

\section{Conclusions}

This course aimed to develop pre-service teachers' awareness of and confidence to embed social and emotional competencies within their daily practice rather than being an add-on to an already crowded curriculum. Within tutorials, tutors 'walked the talk' and set the tone of the classroom and clearly modelled how to embed a range of competencies in their teaching without distracting from the core content to be taught. The results outlined from the analysis of the rationales in the main assessment task in this course showed that $39 \%$ of the pre-service teachers in this study had a growing awareness of social and emotional skills and, in particular, were able to recognise the importance of focusing on the building of students' social and emotional skills to support academic success. Results also showed that these pre-service teachers were also able to identify how to include the teaching of social and emotional skills across and within a broad range of curriculum areas. With calls to have more congruence between what PSTEs are taught in their university degrees and the expectations of the classroom in the area of social and emotional skills warrants further investigation on how this might be achieved.

This study attempted to test the embedded design principle focusing on SES within a pre-service teacher education core course. A further study that used Bain's [18] embedded design principle together with the added dimension of improving PSTEs' sense of efficacy to teach SES through an applied, mastery-based experience (i.e., professional experience placement in the classroom) where the PSTEs were able to receive feedback would provide a greater sense of impact.

Funding: This research received no external funding.

Conflicts of Interest: The authors declare no conflict of interest. 


\section{References}

1. Greenberg, M.T.; Weissberg, R.P.; O’Brien, M.U.; Zins, J.E.; Fredricks, L.; Resnik, H.; Elias, M.J. Enhancing school-based prevention and youth development through coordinated social, emotional, and academic learning. Am. Psychol. 2003, 58, 466-474. [CrossRef] [PubMed]

2. Newman, J.; Dusenbury, L. Social and Emotional Learning (SEL): A Framework for Academic, Social, and Emotional Success. In Prevention Science in School Settings; Springer: New York, NY, USA, 2015; pp. 287-306.

3. Collaborative for Academic, Social and Emotional Learning (CASEL). CASEL Guide: Effective Social and Emotional Learning Programs_-Preschool and Elementary School Edition; Collaborative for Academic, Social and Emotional Learning (CASEL): Chicago, IL, USA, 2013.

4. Durlak, J.A.; Weissberg, R.P.; Dymnicki, A.B.; Taylor, R.D.; Schellinger, K.B. The impact of enhancing students' social and emotional learning: A meta-analysis of school-based universal interventions. Child Dev. 2011, 82, 405-432. [CrossRef] [PubMed]

5. Sklad, M.; Diekstra, R.; Ritter, M.D.; Ben, J.; Gravesteijn, C. Effectiveness of school-based universal social, emotional, and behavioral programs: Do they enhance students' development in the area of skill, behavior, and adjustment? Psychol. Sch. 2012, 49, 892-909. [CrossRef]

6. Bear, G.G.; Watkins, J.M. Developing self-discipline. In Children's Needs III: Development, Prevention, and Intervention; Bear, G.G., Minke, K.M., Eds.; National Association of School Psychologists: Bethesda, MD, USA, 2006; pp. 29-44.

7. Blakemore, S.J.; Mills, K.L. Is adolescence a sensitive period for sociocultural processing? Annu. Rev. Psychol. 2014, 65, 187-207. [CrossRef] [PubMed]

8. Schonert-Reichl, K.; Kitil, J.; LeRose, M.; Sipl, M.; Sweiss, L.; Teia, Z.; Sauve, J. Social and Emotional Learning and Teacher Education: What Do We Know and Where Do We Go from Here? Bosworth, K., Ed.; White paper prepared for HopeLab; The University of British Columbia: Vancouver, BC, Canada, 2016.

9. Yeager, D.S. Social and Emotional Learning Programs for Adolescents. The Future of Children, 73-94. Psychol. Sch. 2017, 49, 892-909. Available online: https://www.jstor.org/stable/44219022 (accessed on 10 June 2018).

10. Collaborative for Academic, Social and Emotional Learning (CASEL). CASEL Guide: Effective Social and Emotional Learning Programs-Middle and High School Edition; Collaborative for Academic, Social and Emotional Learning (CASEL): Chicago, IL, USA, 2015.

11. DePaoli, J.L.; Atwell, M.N.; Bridgeland, J. Ready to Lead: A National Principal Survey on How Social and Emotional Learning Can Prepare Children and Transform Schools; Civic Enterprises with Hart Research Associates: Washington, DC, USA, 2017.

12. Anderson, M. Social-Emotional Learning and Academics: Better Together. 2015. Available online: http:/ / www.ascd.org/publications/educational_leadership/oct15/vol73/num02/Social-Emotional_ Learning_and_Academics@_Better_Together.aspx (accessed on 20 April 2018).

13. Jennings, P.; Greenberg, M. The Prosocial Classroom: Teacher Social and Emotional Competence in Relation to Student and Classroom Outcomes. Rev. Educ. Res. 2009, 79, 491-525. [CrossRef]

14. National Middle School Association. This We Believe: Keys to Educating Young Adolescents. National Middle School Association; National Middle School Association: Westerville, OH, USA, 2010.

15. Luke, A.; Elkins, J.; Weir, K.; Land, R.; Carrington, V.; Sole, S.; Pendergast, D.; Kapitzke, C.; van Kraayenoord, C.; Moni, K.; et al. Beyond the Middle: A Report about Literacy and Numeracy Development of Target Group Students in the Middle Years of Schooling. Department of Education, Science and Training: Canberra, Australia, 2003.

16. Biesta, G. Pragmatism and the philosophical foundations of mixed methods research. In Sage Handbook of Mixed Methods in Social and Behavioral Research, 2nd ed.; Greene, J.C., Hall, J.N., Tashakkori, A., Teddlie, C., Eds.; Sage: Thousand Oaks, CA, USA, 2010; pp. 95-118.

17. Lave, J.; Wenger, E. Situated Learning: Legitimate Peripheral Participation; Cambridge University Press: Cambridge, UK, 1991; Volume 521423740. 
18. Bain, A. The Self-Organising School: Next Generation Comprehensive School Reform; Rowman \& Littlefield Education: Lanham, MD, USA, 2007.

19. Dweck, C. Mindset: How You Can Fulfil Your Potential; Robinson: London, UK, 2012.

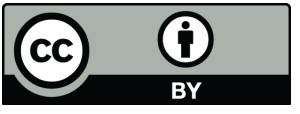

(C) 2018 by the author. Licensee MDPI, Basel, Switzerland. This article is an open access article distributed under the terms and conditions of the Creative Commons Attribution (CC BY) license (http://creativecommons.org/licenses/by/4.0/). 